\title{
Protective Clothing in Hot Environments
}

\author{
Ingvar HOLMÉR
}

Thermal Environment Laboratory, EAT, Department of Design Sciences, Lund University, Box 110, 22100 Lund, Sweden

Received March 11, 2006 and accepted April 21, 2006

\begin{abstract}
The high level of protection required by personal protective clothing (PPC) severely impedes heat exchange by sweat evaporation. As a result work associated with wearing PPC, particularly in hot environments, implies considerable physiological strain and may render workers exhausted in a short time. Recent development of algorithms for describing the heat transfer, accounting for pumping and wind effects, comprises improvement of the prediction of thermal stress. Realistic corrections can then be made to the available measures of thermal insulation and evaporative resistance of a given clothing ensemble. Currently this information is incorporated in international standards for assessment of thermal environments. Factors, such as directional radiation and wetting of layers, were studied in a recently completed EU research project. The development of advanced thermal manikins and measurement procedures should provide better measures for predictive models. As with all methods and models, the results need validation in realistic wear trials in order to prove their relevance and accuracy.
\end{abstract}

Key words: Protective clothing, Heat stress, Prediction models, Climate indices, Physiological strain, Standards

\section{Introduction}

In many jobs workers are required to use personal protective clothing (PPC) to prevent harmful exposures to physical and chemical hazards. It is a requirement for the safety of industrial work, that PPC offers sufficient protection. Much effort has been made to develop methods for determination of the protection factor of different types of PPC and several international standards have been developed or are under development both by the international (ISO) and the European standardisation organisations (CEN). However, it is also important that PPC meets certain ergonomics requirements, so that protection is not compromised by increased physiological or mental strain, impaired performance or increased discomfort. This is particularly true for PPC.

During the last decades the interest in clothing research has grown. Several international conferences have been organized and a great number of scientific articles have been published. The European Society for Protective Clothing organizes a conference every third year ${ }^{1,2)}$ An anthology was recently published on Textiles for Protection ${ }^{3}$. A review on protective clothing and heat stress was published in 19954) and updated for a conference in Adelaide in 20035). This paper provides another update of these two papers and a compilation of new research on protective clothing against heat and chemical agents with emphasis on their effects on thermal balance and performance.

\section{Environmental Stress and Protective Clothing}

The thermal homeostasis of the body is a result of the balance between heat production and heat dissipation. The primary factors of importance for this balance are the energy metabolism, clothing thermal properties and ambient climatic conditions. Several models (or thermal indices) have been developed to compute this interaction and its effect on the body, taking most of these factors into account.

Protective clothing serves the purpose of eliminating or reducing the effects of environmental stress factors. Protection against physical and chemical agents in most cases implies the use of special fabrics and various treatments of 
the fabrics, rendering them highly impermeable to water vapour. An adequate protection therefore is often obtained only at the expense of considerable restrictions on body heat balance.

Standard test methods are available for the evaluation of the protective properties of fabrics. Most of these standards are developed by ISO/TC94/SC15 and CEN/TC162. For an overview of standards visit their websites ${ }^{6,7)}$. Both organisations work actively to coordinate work and harmonize standards. For an overall assessment of the performance of PPC, these methods must be complemented by the evaluation of the ergonomic and thermal function of the full ensembles on subjects or manikins ${ }^{8,9}$.

\section{Heat Balance and Heat Exchange}

Human heat production must be balanced by an equal amount of heat loss to the environment in order to preserve a constant body temperature. The heat balance of the human body is described by equation 1 .

$$
S=M-W-R E S-E-R-C-K .
$$

where $\mathrm{S}$ is the change in energy content of the body, $\mathrm{M}$ is the energy metabolism, $\mathrm{W}$ is external mechanical work, RES is respiratory heat exchange, $\mathrm{E}$ is evaporative heat exchange, $\mathrm{R}$ is radiation heat exchange, $\mathrm{C}$ is convective heat exchange, and $\mathrm{K}$ is conductive heat exchange. Units may be given in Joule or Watt. Common is to consider the rate of energy change per unit time and body surface area-Watts $/ \mathrm{m}^{2}$.

Factors of importance for the heat exchange between the human body and the environment are illustrated in Table 1. The first row lists the principal factors related to man, clothing and environment that are found in most heat balance equations. Additional factors are important, but are often approximated in heat balance equations. Several factors act by modifying the principal factors. Absorption, condensation and ventilation in clothing, for example changes its insulative and evaporative properties.

Metabolic energy production is greatly affected by muscular work. At rest metabolic rate is about $60 \mathrm{~W} / \mathrm{m}^{2}$. In occupational work it may vary from $100 \mathrm{~W} / \mathrm{m}^{2}$ in light work to $250 \mathrm{~W} / \mathrm{m}^{2}$ in very heavy work. In sport activities and during rescue work (firefighting) it can be $300-500 \mathrm{~W} / \mathrm{m}^{2}$ or even higher for short time (1-2 h). Examples of metabolic rates and methods for its determination are given $\mathrm{in}^{10)}$. Since the mechanical efficiency of human physical work is low, values for metabolic rate are almost equal to the heat produced by the body.

The significant forms of heat exchange in most practical situations are by evaporation, convection and radiation. In a simplified analysis of heat balance convection and radiation are often lumped together and the following equation apply.

$$
R+C=\frac{\left(t_{s k}-t_{a}\right)}{I_{T o t}}
$$

where $\mathrm{I}_{\mathrm{Tot}}$ is the thermal insulation $\left(\mathrm{m}^{2 \circ} \mathrm{C} / \mathrm{W}\right), \mathrm{t}_{\mathrm{sk}}$ is the skin temperature and $\mathrm{t}_{\mathrm{a}}$ is the ambient temperature (both in ${ }^{\circ} \mathrm{C}$ ).

$$
E=\frac{\left(p_{s k}-p_{a}\right)}{R_{e t}}
$$

where $\mathrm{R}_{\mathrm{et}}$ is the evaporative resistance $\left(\mathrm{m}^{2} \mathrm{kPa} / \mathrm{W}\right), \mathrm{p}_{\mathrm{sk}}$ is the skin water vapour pressure $(\mathrm{kPa})$ and $\mathrm{p}_{\mathrm{a}}$ is the ambient water vapour pressure $(\mathrm{kPa})$.

The values of $\mathrm{I}_{\text {Tot }}$ and $\mathrm{R}_{\mathrm{et}}$ depend on several factors. For a nude person the properties of the air layer adjacent to the skin determine heat exchange. These properties are well understood and described in standard textbooks ${ }^{11}$. For a dressed person the thermal properties of clothing become significant.

\section{Heat transfer through clothing}

Clothing effects on heat exchange are described, basically, by two properties.

- Thermal insulation is the resistance to heat transfer by convection, radiation and conduction.

- Evaporative resistance is the resistance to heat transfer by evaporation.

1) Thermal insulation

Thermal insulation of a clothing ensemble is determined by the properties of fibre materials and fabric construction, the layers of trapped air in the fabric and the air layers between fabrics and fabric layers. By far, the most important factor is the thickness of trapped, still air layers. Accordingly, a rough measure of thermal insulation is the lateral thickness of the total ensemble.

The mathematical definition of thermal insulation follows from equation 2 and is given by equation 4 . The total insulation value is the sum of the clothing insulation value $\left(I_{c l}\right)$ and the surface air layer insulation $\left(I_{a}\right)$. This latter value is normally defined for the nude body surface and must be corrected for the increasing surface $\left(\mathrm{f}_{\mathrm{cl}}\right)$ when clothing is worn.

$$
\begin{gathered}
I_{\text {Tot }}=\frac{t_{s k}-t_{a}}{R+C} \\
I_{T o t}=I_{c l}+\frac{I_{a}}{f_{c l}}
\end{gathered}
$$


Table l. Factors affecting human heat exchange with the environment

\begin{tabular}{|c|c|c|}
\hline Man & Clothing & Environment \\
\hline Metabolic rate, $\mathrm{M}$ & $\begin{array}{l}\text { Insulation, I } \\
\text { Evaporative resistance, } \mathrm{R}\end{array}$ & $\begin{array}{l}\text { Air temperature, } \mathrm{t}_{\mathrm{a}} \\
\text { Mean radiant temperature, } \mathrm{t}_{\mathrm{r}} \\
\text { Air velocity, } \mathrm{v}_{\mathrm{a}} \\
\text { Water vapour pressure, } \mathrm{kPa}\end{array}$ \\
\hline Mean skin temperature, $\mathrm{t}_{\mathrm{sk}}$ & Clothing area factor, $\mathrm{f}_{\mathrm{cl}}$ & Radiant heat flux \\
\hline Skin wettedness, w & Emissivity, e & Solar radiation \\
\hline Work task & Colour & Precipitation \\
\hline Effective radiation area, $\mathrm{A}_{\mathrm{r}} / \mathrm{A}_{\mathrm{Du}}$ & Absorption & Barometric pressure \\
\hline Relative air velocity, $\mathrm{v}_{\mathrm{ar}}$ & Condensation & \\
\hline Mechanical efficiency & Ventilation & \\
\hline Posture & & \\
\hline
\end{tabular}

Insulation values are measured in $\mathrm{m}^{2}{ }^{\circ} \mathrm{C} / \mathrm{W}$. A popular unit is the clo-unit. A normal indoor clothing with jacket, trousers and vest corresponds to approximately 1 clo (1 clo $=0.155 \mathrm{~m}^{2}{ }^{\circ} \mathrm{C} / \mathrm{W}$ ). Insulation values of selected types of PPC are presented in Table 2. Numerous examples of insulation values are given in ISO9920 ${ }^{12)}$.

Thermal insulation of an ensemble can be accurately measured with a thermal manikin. Typically, $\mathrm{R}+\mathrm{C}$, $\mathrm{t}_{\mathrm{sk}}$ and $t_{a}$ is measured under constant, static conditions in a climatic chamber and insulation is given by equation 4 . The method is described in several international standards ${ }^{12-14}$.

As mentioned $\mathrm{I}_{\mathrm{Tot}}$ and $\mathrm{I}_{\mathrm{cl}}$ are measured under standard conditions with a static, standing manikin. These values, in practice, only apply to dressed persons standing still in calm air. Body motion and wind cause ventilation of the ensemble (pumping effect) that reduces the insulation effect. Walking movements may reduce total insulation by $20-30 \%$. Wind up to $10-15 \mathrm{~m} / \mathrm{s}$ may reduce total insulation by 30 $40 \%$ in a completely windproof ensemble and up to 80 $90 \%$ for an ensemble made of open, porous fabrics ${ }^{15}$.

2) Evaporative resistance

Evaporative resistance is a moisture transfer resistance, as the transferred heat is bound to moisture that evaporates at the skin surface and passes to the environment. Accordingly, properties related to moisture transfer become determinant for the evaporative heat exchange. The most important property of a fabric is the size of pores of the fabric and the thickness of air layers for passage. The smaller the pores and the thicker the air layers, the smaller will be the amount of transferred water vapour and the lesser the heat loss.

Evaporative resistance follows from equation 3 and is defined by equation 6 . The unit is $\mathrm{kPa} \mathrm{m}^{2} / \mathrm{W}$.

$$
R_{e t}=\frac{p_{s k}-p_{a}}{E}=0.06 \cdot \frac{I_{T o t}}{i_{m}}
$$

Evaporative resistance of clothing may be directly measured with subjects ${ }^{16,17}$. It can also be determined on the basis of thermal insulation and the permeability index $\left(i_{m}\right)$ for the fabric or for the ensemble. The permeability index is measured on a "sweating, hot plate"18) or with a sweating, thermal manikin ${ }^{19,20)}$ and expresses the fraction of evaporation that takes place with the sample compared with evaporation through the air layer only.

A few, sweating, thermal manikins are available. Few of them measure according to equation 6 , as $\mathrm{p}_{\mathrm{sk}}$ is difficult to determine. Comparison of measurements with a couple of existing manikins reveals considerable variation ${ }^{21}$. Each of them, however, may give relevant and accurate relative values for comparative use in-house. Recently, a perspiring fabric manikin has been constructed ${ }^{22}$. It allows a simultaneous determination of thermal insulation and evaporative resistance.

A simplified sweating simulation may be carried out by covering the dry manikin with a fully wetted, cotton stocking. The sample clothing is put on top and the measurements are made during the drying-out of the stocking. The procedure seems to function well with high resistance samples, but the risk is obvious that the stocking dries out too quickly for stable records with low resistance samples ${ }^{23)}$.

Examples of evaporative resistance for selected garments systems are given in Table 2.

3) Microclimate effects

The microclimate underneath clothing directly affects the heat exchange at the skin surface and therefore, strongly determines the physiological and psychological responses. Air temperature and water vapour pressure of the 
Table 2. Thermal properties of selected protective clothing ensembles compiled from various sources

\begin{tabular}{|c|c|c|c|c|}
\hline Clothing & $\mathrm{I}_{\mathrm{cl}}$, clo & $\mathrm{I}_{\mathrm{Tot}}$, clo & $\mathrm{i}_{\mathrm{m}}$, n.d. & $\begin{array}{c}\mathrm{R}_{\mathrm{et}}, \mathrm{kPa} \\
\mathrm{m}^{2} / \mathrm{W}\left(10^{-3}\right)\end{array}$ \\
\hline Nude & 0 & 0.7 & 0.50 & 13 \\
\hline Cotton shirt and trousers, underwear, socks, shoes & 0.65 & 1.25 & 0.42 & 28 \\
\hline Coverall, T-shirt, underwear, socks, shoes & 0.84 & 1.41 & 0.42 & 31 \\
\hline $\begin{array}{l}\text { Cotton shirt and pants (flame resistant), underwear, } \\
\text { T-shirt, belt, socks, shoes }\end{array}$ & 1.00 & 1.51 & 0.32 & 44 \\
\hline $\begin{array}{l}\text { Aluminized apron, cotton shirt and trousers, } \\
\text { underwear, socks, shoes }\end{array}$ & 0.77 & 1.33 & 0.38 & 32 \\
\hline $\begin{array}{l}\text { Aluminized coat hip-length, cotton shirt and } \\
\text { trousers, underwear, socks, shoes }\end{array}$ & 1.36 & 1.89 & 0.33 & 53 \\
\hline $\begin{array}{l}\text { Aluminized overjacket and overtrousers, coverall, } \\
\text { long underwear, socks, shoes }\end{array}$ & 1.48 & $2.0\left(1.1^{*}\right)$ & 0.15 & $70^{*}$ \\
\hline $\begin{array}{l}\text { Chemical protective suit (Goretex), coverall, } \\
\text { long undershirt and underpant, socks, shoes }\end{array}$ & 1.4 & $1.9\left(1.3^{*}\right)$ & 0.33 & $37^{*}$ \\
\hline $\begin{array}{l}\text { Chemical protective suit (imperm), coverall, } \\
\text { long undershirt and underpant, socks, shoes }\end{array}$ & 1.4 & $1.9\left(1.1^{*}\right)$ & 0.06 & $180^{*}$ \\
\hline $\begin{array}{l}\text { Firefighter's turnout coverall, trousers, shirt, } \\
\text { underwear, gloves and socks }\end{array}$ & & 2.42 & 0.36 & 62 \\
\hline
\end{tabular}

Values are obtained with measurements on manikins. Values marked with * denote data obtained with measurements on subjects during work in a climatic chamber. Table modified from Holmér ${ }^{4,24)}$.
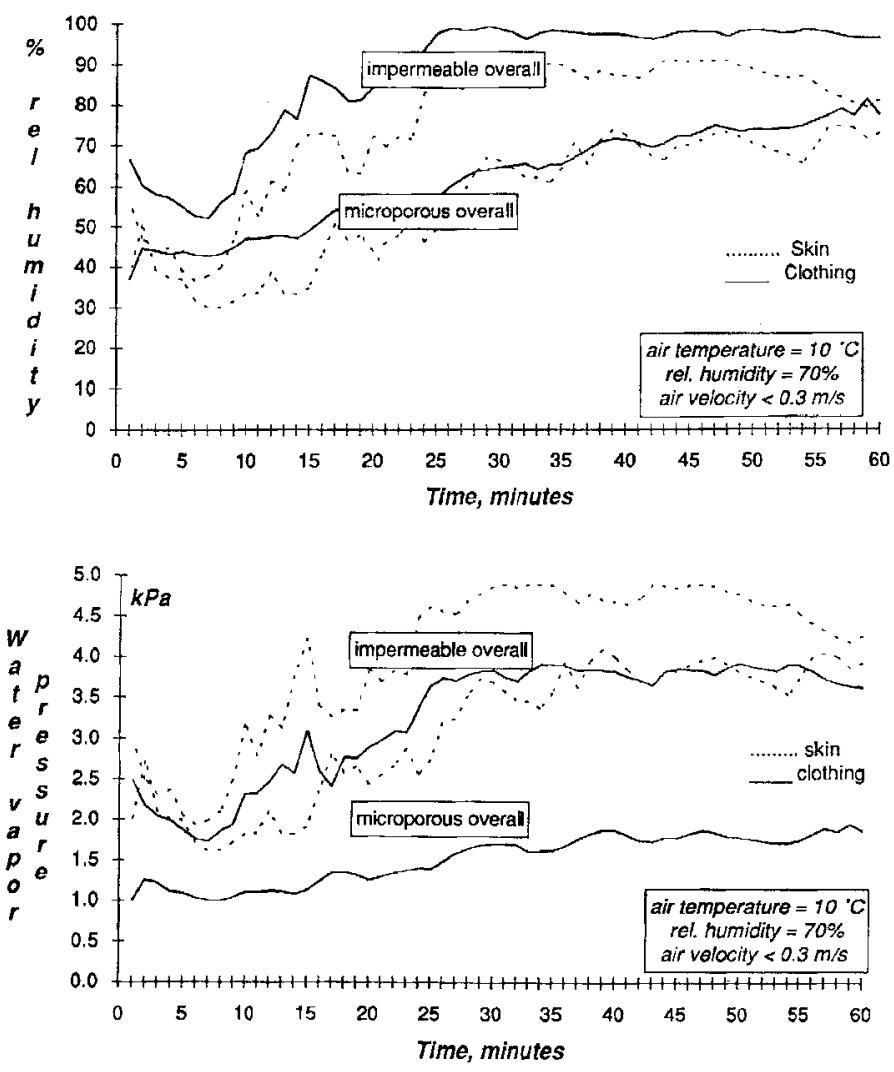

Fig. 1. Water vapour pressure and relative humidity measured on the skin surface (lower back) and underneath clothing surface (corresponding site) during experiments with a subject wearing two kinds of clothing. 
microclimate are well correlated to the thermal properties of the clothing worn. With impermeable fabrics water vapour pressure gradually builds up and, eventually, reaches the saturation pressure (100\% relative humidity) (Fig. 1). Due to the impaired heat exchange a significant increase in microclimate air temperatures as well as skin temperatures may be seen. These simple measurements can be used for relative comparisons of ensemble performance.

The microclimate is greatly affected by the air exchange rate of the microclimate volume. Methods for the measurement of clothing ventilation have been developed and proven successful for the evaluation of $\mathrm{PPC}^{25-29)}$. For comparison of alternative designs of a garment, the tracegas technique, appears to present a quick and reliable technique. It should be emphasized, that ventilation through garment openings represents a particularly important avenue of heat exchange for PPC, when normal heat transfer through the fabric is greatly restricted. The quantitative aspect of microclimate ventilation in terms of actual heat transfer, however, remains to be analyzed with this technique. Umbach (Umbach 1988) measured microclimate ventilation with a 'walking' manikin by comparing heat exchange for clothing with and without its openings being sealed. This method gives valuable information for the assessment of the resultant insulation of clothing.

4) Heat exchange at the clothing surface

The body surface area of the average man is approximately $1.8 \mathrm{~m}^{2}$ (ISO8996). Clothing expands this area and the heat exchange at the clothing surface has to be corrected by the clothing area factor. The factor can be measured but also calculated on the basis of $\mathrm{I}_{\mathrm{cl}}{ }^{12}$. As heat arriving at the clothing surface dissipates from a greater surface area, the effective insulation of the boundary air layer is reduced (see equation 5).

5) Evaporation

Evaporative heat loss comprises a significant means of cooling the body and is of particular importance in hot environments. A sweat evaporation of $1 \mathrm{l} / \mathrm{h}$, theoretically means a heat dissipation of $680 \mathrm{~W}$ (about $380 \mathrm{~W} / \mathrm{m}^{2}$ ) and is sufficient to balance heat production during very heavy work.

Equation 3 can be redefined and also expressed using the moisture permeability index, $i_{\mathrm{m}}$.

$$
E=\frac{\left(p_{s k}-p_{a}\right)}{R_{e t}}=16.7 \cdot i_{m} \cdot \frac{\left(p_{s k}-p_{a}\right)}{I_{T o t}}
$$

It follows immediately from equation 7 that low values for $i_{m}$ and high values for $I_{\text {Tot }}$ quickly reduce evaporative heat loss. Accordingly, impermeable fabrics and thick, insulative clothing allow only small amounts of evaporative heat exchange.
When clothing is less permeable the clothing microclimate eventually becomes saturated and condensation occurs in clothing layers (Fig. 1). In temperate and warm environments this is likely to take place just underneath the outer, impermeable layer. Heat is liberated, increasing the local temperature. Theoretically, the heat gain from condensation slows down conductive heat loss and may aggravate heat stress. However, the closer to the surface condensation takes place, the smaller is the reduction. Most of the heat gain, consequently, is dissipated to the environment. However, the total heat loss is less than if the same amount of water had escaped without condensation. In other words, the efficiency of evaporative cooling is reduced ${ }^{23)}$.

6) Radiation

Radiation heat exchange at the clothing surface is computed by

$$
\begin{aligned}
& R=h_{r} \cdot f_{c l} \cdot\left(t_{c l}-\bar{t}_{r}\right) \\
& h_{r}=\sigma \cdot \varepsilon_{c l} \cdot \frac{A_{r}}{A_{D}} \cdot \frac{\left(t_{c l}+273\right)^{4}-\left(\bar{t}_{r}+273\right)^{4}}{t_{c l}-\bar{t}_{r}}
\end{aligned}
$$

where $\sigma$ is the Stefan-Boltzman constant of $5.67 * 10^{-8}$ $\mathrm{W} / \mathrm{m}^{2} \mathrm{~K}, \varepsilon_{\mathrm{cl}}$ is the emissivity of the surface (n.d.), $\bar{t}_{r}$ is the mean radiant temperature $\left({ }^{\circ} \mathrm{C}\right)$ and $\mathrm{A}_{\mathrm{r}} / \mathrm{A}_{\mathrm{D}}$ is the effective body surface area taking part in radiation heat exchange (n.d.). For a given ensemble the radiation heat exchange is independent of air. The value of $h_{r}$ decreases slightly with decreasing $\mathrm{t}_{\mathrm{cl}}$ and $\bar{t}_{r}$. A typical value of $\mathrm{h}_{\mathrm{r}}$ at room temperature is $4.5 \mathrm{~W} / \mathrm{m}^{2}{ }^{\circ} \mathrm{C}$.

Mean radiant temperature is the average of temperatures of the surfaces surrounding the body, weighted by their projected area. In homogenous environments this temperature is equal to the air temperature. In the presence of hot or cold surfaces of reasonable size or other radiation sources such as the sun or a furnace, mean radiant temperature may differ considerably from the air temperature.

It is clear from the equation that the emissivity plays a significant role in heat exchange. The emissivity of a surface depends on material and surface structure. Polished metals emit much less radiation at a given temperature (10-20\%) in comparison with painted, matte, varnished, or dark surfaces (80-100\%). A polished metal surface may be at a much higher temperature and still emitting less radiant heat than a clothed surface. It is evident, that less radiant heat load is imposed on a person if surrounding surface temperatures are kept low and surfaces are kept clean, metallized and polished.

In Table 3 data for different types of aluminized fabrics are presented ${ }^{30)}$. The ratio between the radiant heat flux 
measured with and without the fabric is measured. It is evident from these data that the capacity to reduce radiant heat flow varies considerably between aluminized fabrics. Vacuum metallized coatings have high reflective power.

The fraction of the body surface area that takes part in radiation heat exchange may be approximated by 0.77 for a standing person when the radiant field is homogeneous ${ }^{31)}$. When radiant heat flux is directional the projected area of the body determines the effective area. In other words, minimizing the body surface area exposed to the source of radiant heat will reduce the thermal load. This is obvious for solar heat load, as the irradiated area of the body surface changes with the azimuth of the sun. The area is smallest when the sun is in zenith and largest at sunrise or sunset. However, the radiation intensity increases with sun elevation. The highest radiation load is achieved when the sun is about $30-40^{\circ}$ above the horizon.

The heat gain by solar radiation is also affected by the colour of the clothing. The energy in the visible spectrum of the sunshine is better absorbed by black, matte fabrics than by white fabrics ${ }^{32)}$. A white fabric transmitted only about $20 \%$ of the total energy from a solar lamp compared to about $40 \%$ for a black fabric. Figure 2 shows the net heat loss from a thermal manikin exposed to direct sunshine, wearing different types of clothing. The reflective garment absorbs much less solar and radiant heat, than the coloured, cotton fabrics. The white coverall reflects more of the solar radiation (visible component) than the black one ${ }^{33)}$ The direct body gain from solar radiation may be up to $100 \mathrm{~W}^{34)}$.

Wetting of clothing complicates the heat transfer process, by gradually reducing clothing insulation and increasing heat conduction. Reduced insulation speeds up radiation and convection heat exchange. Heat losses are increased with wetting but radiation reduces some of this effect (Fig. 3). In moderate and warm environments the resulting effect may be positive and relieve heat strain. At air temperatures higher than skin temperature $\left(35-40^{\circ} \mathrm{C}\right)$ and in the presence of high intensity infra-red radiation, the body may gain heat more rapidly by convection and radiation, aggravating the thermal strain $^{23)}$.

\section{7) Convection}

Convective heat exchange through clothing is determined by

$$
R+C=\frac{t_{s k}-t_{a}}{I_{t, r}}
$$

where $\mathrm{I}_{\text {Tot }}$ is replaced by the resultant insulation value $\mathrm{I}_{\mathrm{T}, \mathrm{res}}$, to account for various walking and wind speeds. Havenith and Nilsson ${ }^{35)}$ compiled data from various studies of wind effectgs on protective garments and developed an algorithm for correction of the static value.
Table 3. Heat flow transmission rates in $\%$ of selected fabrics for protective clothing against low temperature heat radiation ${ }^{30}$

\begin{tabular}{lc}
\hline Material & $\%$ \\
\hline Cotton, no reflective layer & 62 \\
Polyester/cotton, no reflective layer & 55 \\
Woo1, with glossy aluminium foil & 12 \\
Polyester, with matte aluminium foil & 4 \\
Cotton, with aluminium paint & 42 \\
Cotton, vacuum metallized with aluminium & 5 \\
Aramid (Kevlar), vacuum metallized with aluminium & 4 \\
\hline
\end{tabular}

The remaining $\%$ is reflected heat.

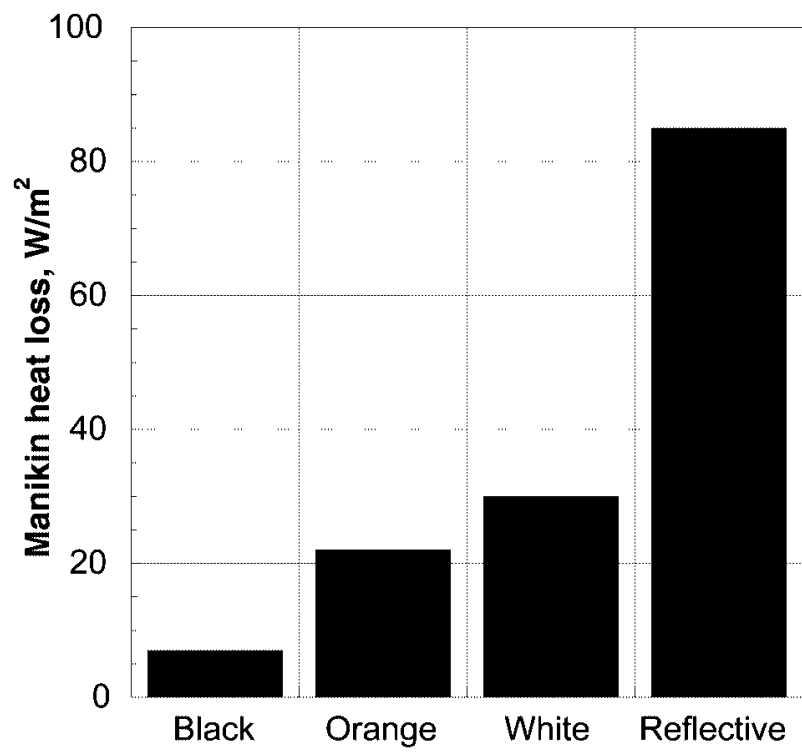

Fig. 2. Measured manikin heat loss when exposed to solar radiation at an angle of about $30-40^{\circ}$ in an air temperature of $10-15^{\circ} \mathrm{C}$ and wind $0.9 \mathrm{~m} / \mathrm{s}$.

Ensembles were of similar design, but differed in terms of surface colour of fabric. "Reflective" was and aluminized fabric. Modified from ${ }^{33)}$.

$$
\begin{aligned}
I_{\text {Tot, res }}= & I_{\text {Tot, static }} \\
& \cdot\left[e^{\left[\left(-0.0512 \cdot\left(v_{a r}-0.4\right)+0.794 \cdot 10^{-3} \cdot\left(v_{a r}-0.4\right)^{2}-0.0639 \cdot w\right) p^{0.434}\right]}\right]
\end{aligned}
$$

$\mathrm{I}_{\mathrm{T}, \mathrm{res}}$ is the resultant insulation value for clothing used in the real situation, $\mathrm{I}_{\text {Tot, static }}$ is the standard insulation value, $\mathrm{w}$ is the walking speed in $\mathrm{m} / \mathrm{s}$ and $p$ is the air permeability in $1 /\left(\mathrm{m}^{2} \mathrm{~s}\right)$ of the outer layer.

Wind also interferes with radiation. At higher wind speeds the net heat gain from radiation reduces ${ }^{36}$.

\section{Physiological strain}

With restrictions imposed upon the body heat exchange, physical work in protective clothing becomes strainful. In 


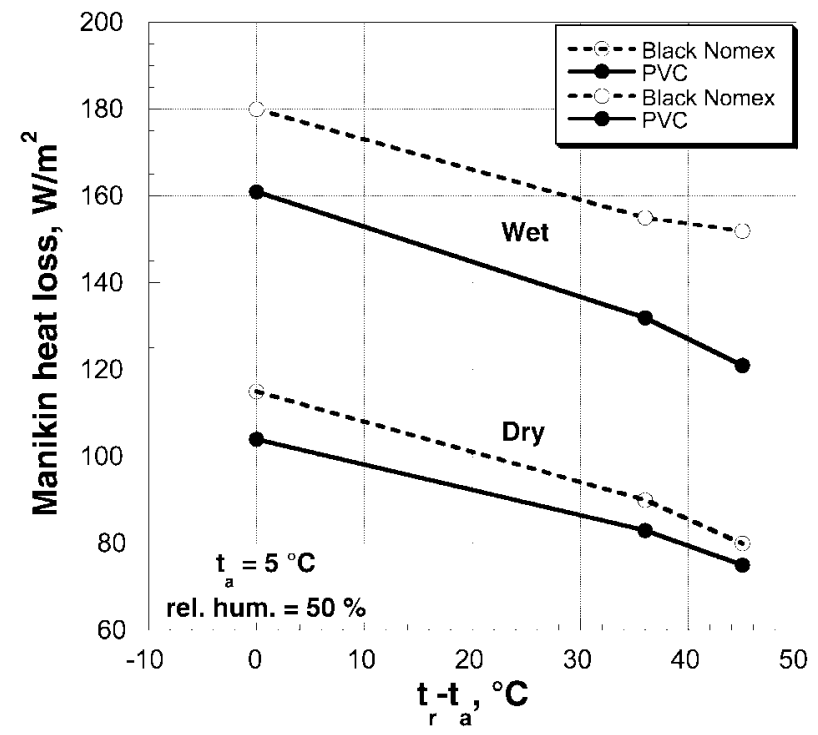

Fig. 3. Effect of long-wave infrared radiation on manikin heat loss with dry and wet underwear, respectively.

Ensembles were of similar design made of permeable nomex fabric and impermeable PVC fabric. Modified from ${ }^{(23)}$.

addition, the bulk and weight of most types of PPC increase the energy cost of work by up to $20 \%{ }^{37}$.

In one investigation subjects walked at $3 \mathrm{~km} / \mathrm{h}$ on a treadmill (M approx. $\left.=150 \mathrm{~W} / \mathrm{m}^{2}\right)$, dressed in any of four types of chemical protective clothing ${ }^{38}$. The four types of clothing that were studied were of identical design and worn on top of polypropylene underwear, cotton coverall, socks and shoes. Subjects breathed through a full face mask from a self-contained, compressed air breathing apparatus. Total weight of PPE was approximately $20 \mathrm{~kg}$. The four types of PPC were:

1. PVC impermeable coverall made of polyamid, unventilated

2. GT semipermeable coverall made of microporous fabric (Goretex), unventilated

3. PVCN same as PVC, ventilated with compressed air at $300 \mathrm{l} / \mathrm{min}$

4. GTN same as GT, ventilated with compressed air at $3001 / \mathrm{min}$

Subjects walked for $90 \mathrm{~min}$ at an air temperature of $45^{\circ} \mathrm{C}$ and $60 \mathrm{~min}$ at $65^{\circ} \mathrm{C}$, respectively. Temperatures and sweating reactions are illustrated in Fig. 4. Mean skin temperature and rectal temperatures increase gradually with the PVCsuit. After about 10 min of work with the GT -suit the subject did benefit from the cooling of evaporating sweat through the microporous clothing. The use of microporous material and ventilation of garment both significantly improved heat exchange, hence reducing physiological strain and improving

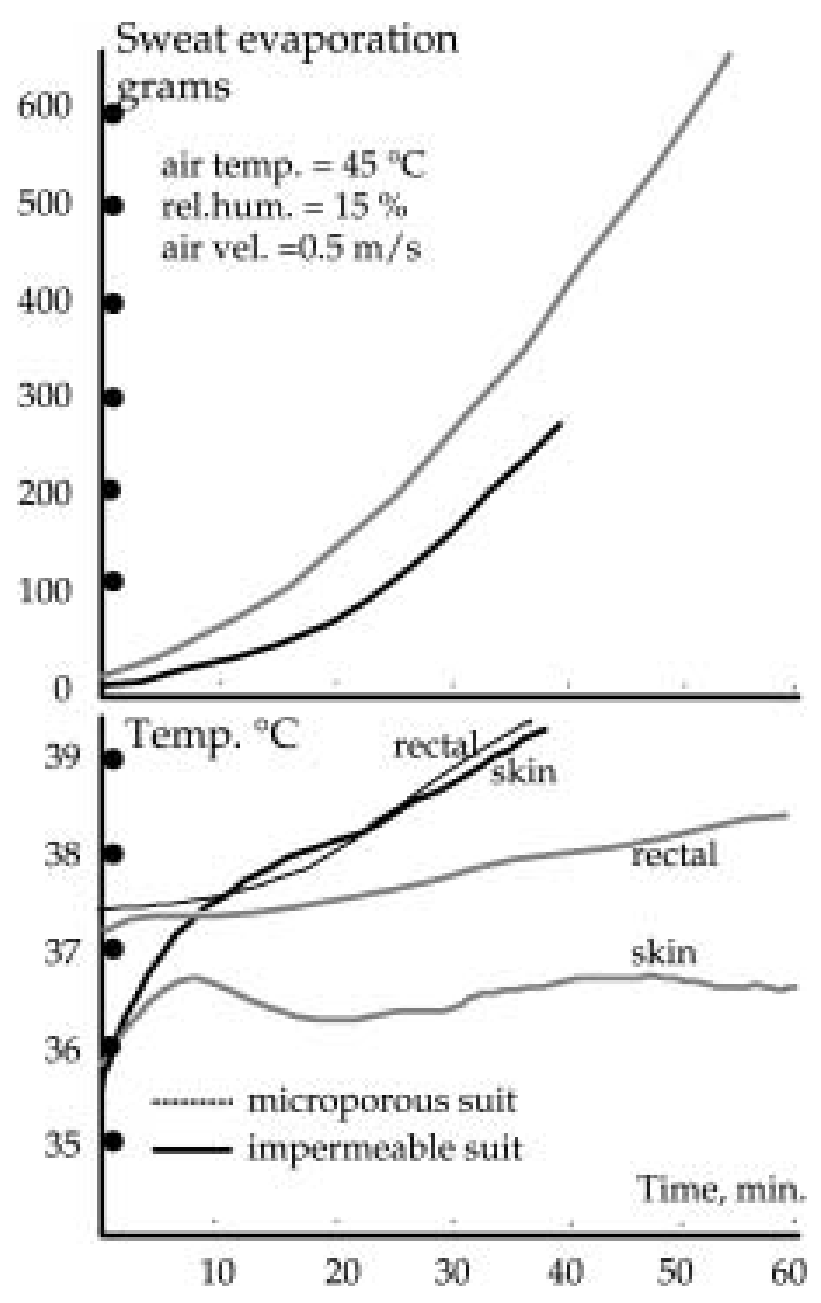

Fig. 4. Responses of one subject to treadmill walking in $45^{\circ} \mathrm{C}$ air temperature wearing two types of protective clothing (PVC and GT).

The upper panel shows the weight change of the subject due to sweat evaporation and the lower panel shows the mean skin temperature and rectal temperature.

Table 4. Heat storage rate (S) and tolerance time during work in protective clothing

\begin{tabular}{ccccc}
\hline Protective clothing & $\begin{array}{c}45^{\circ} \mathrm{C} \\
\mathrm{S}, \mathrm{W} / \mathrm{m}^{2}\end{array}$ & $\begin{array}{c}45^{\circ} \mathrm{C} \\
\text { Time, min }\end{array}$ & $\begin{array}{c}65^{\circ} \mathrm{C} \\
\mathrm{S}, \mathrm{W} / \mathrm{m}^{2}\end{array}$ & $\begin{array}{c}65^{\circ} \mathrm{C} \\
\text { Time, min }\end{array}$ \\
\hline PVC & 104 & 45 & - & - \\
GT & 19 & 246 & 123 & 38 \\
PVCN & 11 & 416 & 92 & 50 \\
GTN & 9 & 516 & 36 & 130 \\
\hline
\end{tabular}

Tolerance time is calculated by $\mathrm{Q} / \mathrm{S}$, where $\mathrm{Q}$ is the limit heat storage of $80 \mathrm{Wh}$ for the average $\operatorname{man}^{39}$. 
tolerance to work in the heat. The best results were obtained when ventilation and microporous material were combined (GTN). Subjects were able to work for $60 \mathrm{~min}$ at $65^{\circ} \mathrm{C}$, with only marginal heat storage and physiological strain (Table 4).

Figure 5 reports the rectal and skin temperature of a firefighter working in two types of clothing in a climatic chamber (Holmér, unpublished data). One experiment was with long-sleeved and long-legged underwear and another experiment was with turnout coat and trousers on top of the underwear, helmet and breathing apparatus. Skin temperature reaches $40^{\circ} \mathrm{C}$ and rectal temperature $39^{\circ} \mathrm{C}$ in the turnout gear in 25 min and the subject must stop due to exhaustion. Skin temperature drops rapidly outside the chamber afterwards, whereas rectal temperature continues to rise for 7-8 $\mathrm{min}$. The temperature rise is much smaller with the underwear alone. Rectal temperature reaches $38.3^{\circ} \mathrm{C}$ after $30 \mathrm{~min}$.

\section{Prediction Models and Indices}

A large number of heat indices have been proposed ${ }^{11)}$. Most of them assume normal work clothing and do not account for the effect of clothing with special thermal properties e.g. PPC. Two indices are recommended as ISOstandards-WBGT ${ }^{40)}$ and Predicted Heat Strain, PHS $^{31)}$.

The WBGT-index assumes normal, one layer work clothing. Based on experimental work, corrections of the WBGT -value related to type of PPC worm, have been proposed $^{41,42)}$, i.e. in general the temperature limit value lowers with PPC. Corrections, however, do not have the same meaning in a hot humid or in a hot dry environment. Since the main problem of PPC in moderate and hot environments is the impedance of evaporative heat exchange, it is essential for a predictive model or an index to account for the evaporative resistance of clothing (equation 7).

ISO 7933 requires input of values for clothing thermal insulation and evaporative resistance. As soon as these values are known a calculation of heat balance can be made for the actual work, clothing and climate. Required evaporation rate is compared with possible evaporation rate for heat balance in the actual condition. If possible evaporation rate is lower, the body will gain heat and the increase in core temperature is calculated. Time is calculated for a core temperature increase of $1^{\circ} \mathrm{C}^{31)}$.

The effect of impermeable and permeable clothing on work time is illustrated in Fig. 6. ISO7933 was used, with correction algorithms for clothing insulation and evaporative resistance, to analyze work under various hot conditions. It

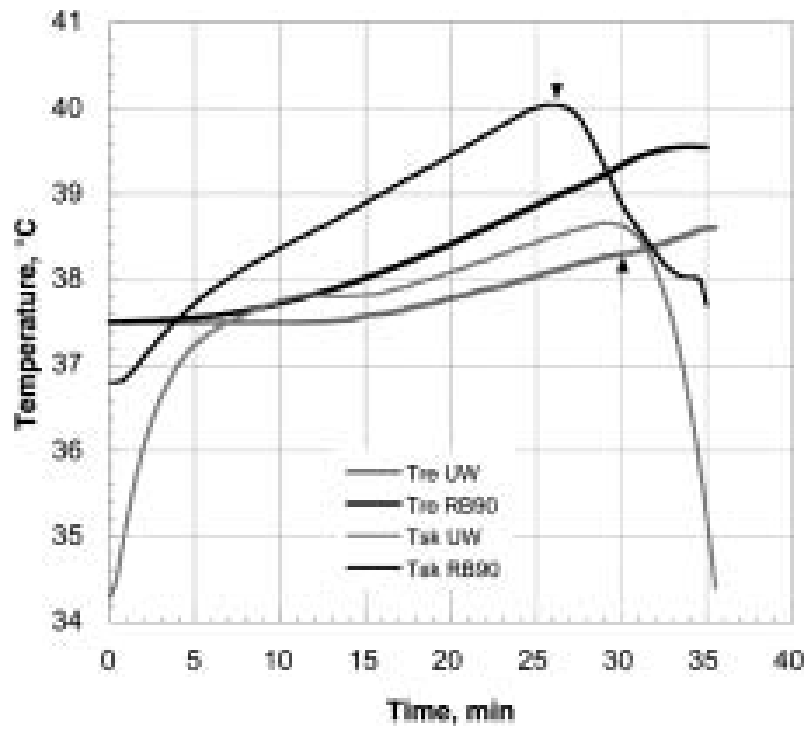

Fig. 5. Change of skin and rectal temperature with time during walking $(5 \mathrm{~km} / \mathrm{h})$ in two types of clothing in $55^{\circ} \mathrm{C}$ air temperature and $30 \%$ relative humidity.

UW is long underwear and RB90 is a firefighter's turnout gear worn on top of UW. Arrows indicate break time.

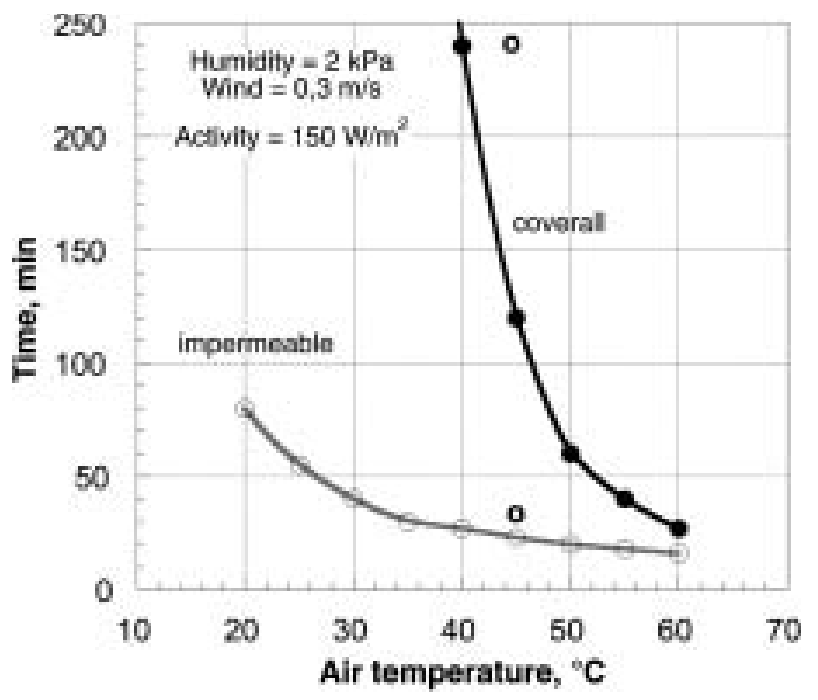

Fig. 6. Recommended times for work in impermeable (open circles) and double cotton coverall.

Limit was defined as an increase in core temperature by $1^{\circ} \mathrm{C}$. The two open, bold circles refer to the experiments reported in Table 4.

is readily seen that work that requires encapsulating clothing can only be performed for short periods of time, irrespective of the ambient temperature conditions. Even light work at $150 \mathrm{~W} / \mathrm{m}^{2}$ can only be performed up to an hour even at normal indoor temperatures. The double cotton coveralls allow much longer work times at temperatures below $45^{\circ} \mathrm{C}$. At very 
high temperatures differences in properties between garments disappear due to the overwhelming external heat load. Results of this kind may give guidance to establish work cycles in warm environments.

ISO 7933 in its present version does not account for the specific thermal events that may occur when PPC is used in hot environments. Phenomena such as moisture absorption and condensation, directional radiation, solar radiation, and their interaction with for example wind, may have significant influence on heat exchange and impair the accuracy of the prediction of thermal strain. Also the effect of weight and bulk on metabolic rate requires consideration. The recently completed EU research project ThermProtect ${ }^{23}$ ) addressed these problems and forthcoming publications will provide improved scientific basis for the subsequent revision of ISO 7933 and similar models. This should improve their accuracy and application field.

\section{References}

1) Kuklane K, Holmér I (2000) Ergonomics of protective clothing. In: Proceedings of NOKOBETEF 6 and 1st ECPC, Solna, Sweden.

2) Richards M (2003) Challenges of protective clothing. 2nd European Conference on Protective Clothing, Montreux, Switzerland.

3) Scott R (2005) Textiles for protection. Woodhead, Cambridge.

4) Holmér I (1995) Protective clothing and heat stress. Ergonomics 38, 166-82.

5) Holmér I (2003) Protective clothing and thermal stress. 21st Annual Conference of the Australien Institute of Occupational Hygienists, Edwards J (Ed.), CD Paper 203, AIOH, Adelaide.

6) CEN (2006) Harmonized standards on protective equipment. Available from http: www.cenorm.be/CENORM/ BusinessDomains/Technical CommitteesWorkshops/ C E N T e c h n i c a $1 \mathrm{Co} m \mathrm{mit} \mathrm{t}$ e $\mathrm{s} /$ CENTechnicalCommittees.asp ? param $=6143 \&$ title $=$ CEN\%2FTC+162. Accessed Apr., 2006.

7) ISO (2006) TC159 Ergonomics. Available from http: www.iso.ch/iso/en/stdsdevelopment/tc/tclist/ TechnicalCommitteeDetailPage.TechnicalCommittee Detail?COMMID=2606. Accessed Apr., 2006.

8) Umbach KH (1988) Physological tests and evaluations models for the optimization of the protective clothing. In: Environmental ergonomics, Mekjavic IB, Banister EW, Morrison JB (Eds.), 139-61, Taylor \& Francis, New York.

9) prEN-13921/4 (2003) Personal protective equipment Ergonomic principles. Part 4-Thermal characteristics. Centre Europeen de Normalisation, Brussels.

10) ISO-8996 (2004) Ergonomics-Determination of metabolic heat production. ISO, Geneva.

11) Parsons KC (2003) Human thermal environments. Taylor \& Francis, Hampshire, UK.
12) ISO-9920 (2006) Ergonomics of the thermal environmetsEstimation of the thermal insulation and evaporative resistane of a clothing ensemble. ISO, Geneva.

13) EN-342 (2004) Protective clothing-Ensembles for protection against cold. CEN, Brussells.

14) ISO-15831 E (2003) Thermal manikin for measuring the resultant basic thermal insulation. ISO, Geneva.

15) Nilsson HO, Anttonen H, Holmér I (2000) New algorithms for prediction of wind effects on cold protective clothing. NOKOBETEF 6, 1st ECPC, 17-20, Norra Latin, Stockholm, Sweden.

16) Kenney WL, Lewis DA, Hyde DE, Dyksterhouse TS, Armstrong CG, Fowler SR, Williams DA (1987) Physiologically derived critical evaporative coefficients for protective clothing ensembles. J Appl Physiol 63, 1095-9.

17) Holmér I, Elnäs S (1981) Physiological evaluation of resistance to evaporative heat transfer by clothing. Ergonomics 24, 63-74.

18) ISO-11092 (1993) Textiles-Physiological effectsMeasurement of thermal and water-vapour resistances under steady-state conditions (sweating guarded hotplate test), ISO, Geneva.

19) Breckenridge JR, Goldman RF (1977) Effect of clothing on bodily resistance against meteorological stimuli. In: Progress in Human Biometeorology, Tromp J (Ed.), 194-208, Sweits \& Zeitlinger Amsterdam.

20) McCullough EA, Jones BW, Tamura T (1989) A data base for determining the evaporative resistance of clothing. ASHRAE Transactions 95, 316-28.

21) McCullough E (2001) Interlaboratory study of sweating manikins. 5th European Conference on Protective Clothing and NOKOBETEF7, Montreux, Switzerland.

22) Fan J, Chen Y, Zhang W (2001) A perspiring fabric thermal manikin: its development and use. 4th International Meeting on Thermal Manikin, S:t Gallen, Switzerland.

23) Havenith G, Holmér I, Meinander H, den Hartog E, Richards M, Bröde P, Candas V (2006) Assessment of thermal properties of protective clothing and their use. EU Final Report Contract No: G6RD-CT-2002-00846. 108, Brussels.

24) Holmér I (1996) Protective clothing and heat stress. 25th International Congress on Occupational Health 1, 22 (Abstract).

25) Birnbaum RR, Crockford GW (1978) Measurement of the clothing ventilation index. Appl Ergonomics 9, 194-200.

26) Bouskill LM (1999) Clothing ventilation and human thermal response (Ph.D. thesis). Loughborough University, Loughborough.

27) Lotens WA, Havenith G (1988) Ventilation of rainwear determined by a trace gas method. In: Environmental ergonomics, Mekjavic IB, Banister EW, Morrison JB (Eds.), Taylor \& Francis, New York.

28) Reischl U, Stransky A (1980) Assessment of ventilation characteristics of standard and prototype firefighter protective clothing. Textile Res J 50, 1980.

29) Sullivan PJ, Mekjavic IB (1992) Temperature and humidity 
within the clothing microenvironment. Aviat Space Environ Med 63, 186-92.

30) Bernsköld A, Forsberg K, Jensen A, Schultz B (1983) Skyddsbeklädnad mot värmestrålning: Enheten för Arbetsvetenskap (in Swedish).

31) ISO-7933 (2002) Hot environments-Analytical determination and interpretation of thermal stress using calculation of predicted heat strain, PHS. 39, ISO, Geneva.

32) Joegard H (2004) Solenergitransmission i textila material. (Solar energy transmission in textile materials) 38, Textile Department, Boras university, Borås.

33) Kuklane K, Holmer I, Gao C (2006) Effects of naturla solar radiation on manikin heat exchange. 3rd European conference on protective clothing, Gdynia, Warsaw.

34) Nielsen B, Klassow K, Aschengreen FE (1988) Heat balance during exercise in the sun. Eur J Appl Physiol 58, 189-96.

35) Havenith G Nilsson H (2004) Correction of clothing insulation for movement and wind effects - a metanalysis. Eur J Appl Physiol 92, 636-40.

36) Havenith G, Wang $X$, Thermprotect network (2005) Interaction effects of radiation and convection measured by a thermal manikin wearing protective clothing with different radiant properties. 47-50, 3rd International conference on Human-Environment systems, Tokyo.

37) Dorman L, Havenith G, Network T (2005) The effects of protective clothing on metabolic rate. Environmental Ergonomics XI. eds. by Holmér I, Kuklane K Gao C, 82-5, Lund University, Ystad, Sweden.

38) Sköldström B, Holmér I (1984). A protective garment for hot environments with improved evaporative heat transfer. In: Aspect medicaux et biophysiques des vetements de protection, Lyon-Bron. 289-94, Centre de Recherches du Service de Santé des Armées.

39) Henane R, Bittel J, Viret R, Morino S (1979) Thermal strain resulting from protective clothing of an armored vehicle crew in warm conditions. Aviat Space Environ Med 50, 599-603.

40) ISO-7243 (1994) Hot environments-Estimation of the heat stress on working man, based on the WBGT-index. 9, ISO, Geneva.

41) Kenney WL (1987) WBGT adjustments for protective clothing. Am Ind Hyg Assoc J 48, A576-7.

42) ACGIH (2002) TLVs and BEIs-Threshold limit values for chemical substances and physical agents. Heat and Cold. ACGIH, Cincinnati. 